A publication of the Muma College of Business | University of South Florida

\begin{tabular}{lcc}
\hline Volume 6 & Number 21 & 20 JULY 2021 \\
\hline
\end{tabular}

JEREMY BESS, DEVA BOONE, CHASE DAFNIS, KRISTIAAN GAINES, DANIEL KIGER

\title{
THE TICKETING SYSTEM THAT COULDN'T ${ }^{1}$
}

\author{
Implementing new company-wide client management software across a global office is \\ challenging. Will a time restraint limit the right choice?
}

"There's not enough time for this!" Cary Wilson, the Director of IT for Global Convergence, Inc (GCI), had just told the CTO that his assignment was impossible. The executive team had ordered him to merge the US and Romanian technology systems by the end of the year. These systems had been built for different purposes, and Wilson likened this to merging a Chevy with a Harley.

GCI was a global IT services organization that provided and supported all aspects of global enterprise networks throughout 176 countries. The company had regional offices in Florida, Romania, Brazil, and Singapore, and maintained two network operations centers in Cluj-Napoca, Romania and Tampa, FL.

Wilson, a 5-year veteran at GCI, was responsible for the organization's information technology department including development, infrastructure, information security, and support of all applications and enterprise systems. Basically, he led the online tools that GCI's employees and clients used. The offices in the US and Romania used very different technologies. Each region was running independently, with its own local infrastructure and processes, and there was little interaction or collaboration among the two regions. Unfortunately, the US help desk \& project management solution was going end-of-life within 1-year. The executive leadership saw this as the perfect opportunity to implement a global unified help desk and project delivery solution.

GCI needed a system that would serve as a selling tool to clients and allow project managers to efficiently manage and track performance of client projects. Wilson had been told to merge the current disparate systems in a short period of time. But how long would it take and how much would it cost? Furthermore, who were the most important stakeholders: the internal teams or external clients? Should the company benchmark between sites or against its competitors? And how important, really, was client management software?

\footnotetext{
${ }^{1}$ Copyright (C 2021, Jeremy Bess, Deva Boone, Chase Dafnis, Kristiaan Gaines, Daniel Kiger. This case was prepared for the purpose of class discussion, and not to illustrate the effective or ineffective handling of an administrative situation. Names and some information have been disguised. This case is published under a Creative Commons BY-NC license. Permission is granted to copy and distribute this case for non-commercial purposes, in both printed and electronic formats.
} 


\section{Global Convergence Inc.}

"Nothing is cookie cutter... It depends on what you're trying to do and how you're trying to do it, with the product you're trying to do it with." - Cary Wilson, GCI

\section{IT Consultancy Services}

Founded in 2008, Global Convergence Inc. was an international player in the IT services industry, designing and supporting managed services solutions. By 2020 Global Convergence Inc. was able to achieve in upwards of $\$ 43$ million in annual sales. This was no easy feat for a company who had to compete with Vology, Dimension Data NTT, HCL Technologies, Verizon, and Accenture. Some of these companies were vastly bigger than GCI, but many of these competitors did not focus on the core competencies that GCI was able to create. Their focus and ultimate efficiencies that promoted strong synergies across their departments allowed GCI to offer lower cost services and products that many of the bigger firms were unwilling to operate in (with lower margin opportunities). Many times, GCI won bids on projects against some of these extremely large companies, which proved they found a way to operate with smaller margins and still be highly successful.

GCI managed or assisted with aspects of businesses' IT needs, with a focus toward voice management services such as Voice over IP (VoIP). They specialized in being nimble and creative, and prided themselves on providing value to clients that were not in the IT sector. GCI offered a suite of solutions from network management to on-site consultations. For network management, their teams could remotely monitor and maintain the data infrastructure of a company network. If something seemed wrong, the client could interact directly with GCI through a help-desk type solution. Often, though, GCI could detect the problem before the client - GCI employees took great pride in the fact that their monitoring systems could detect anomalies and notify the client immediately, before they even knew there was an issue. For a client who did not specialize in network capabilities and maintenance, there was huge value in having GCI monitor their systems. GCI could assist with digital transformations and migrating legacy networks to new and improved networks, including installation, technical testing and integration, and project management.

For those clients who wanted to have someone working directly on-site or with their team, GCI provided firms with on-site or remote engineers working as an extension of the client's internal team. Clients often would not know how to hire for that position. GCI used their decades of experience in the field to find local associates who understood the industry and could assist the client.

\section{What made them a winner?}

GCIs network of global partners allowed clients to support all their locations with a single IT partner. This global support provided clients with a competitive advantage for international distribution or global expansion of their network operations.

GCI was listed as a CISCO Gold Partner, allowing them to show the breadth of their skills across certain technologies. This proven trust allowed them to be at the top of the list when a company was looking for specific IT needs. Once a company began to work with GCI, their suite of products (in the form of procurement) and services enabled them to keep the competition at the door (Exhibit 1).

With their team of nearly 80 employees all over the world and the skills required to be a top vendor to many countless firms, their success was an integral part of the Tampa Bay community. 


\section{Key Competitors}

GCI's global competitors included well-known international corporations such as Verizon, Accenture, NTT (acquired Dimension Data in 2010), and HCL Technologies (Exhibit 2). Within the US, GCI also competed with Vology. Overall, the industry was fragmented: according to research by Dun \& Bradstreet, in the US the 50 largest companies accounted for $40 \%$ of US revenue (First Research, 2020). Though there were big players, the market was also flooded with small to medium-sized companies like GCI.

Although Verizon and Accenture offered similar services as GCI, they had a much broader portfolio of services and product offerings that made it difficult to compare these corporations. Dimension Data and HCL were important competitors because their overall strategies focused primarily on the same services that GCI provided and they continued to execute strategies to increase global market share in those areas. In 2019, NTT's parent company formally joined 28 other companies and brands from 70+ countries and regions worldwide, rebranding as NTT. By leveraging strong brand equity, they could offer more technology solutions to clients throughout the Americas region and around the globe and do so at a faster pace and an even larger scale. (NTT, 2019) HCL operated in the same regions as GCI and was expected to further expand its operations in Australia and New Zealand by announcing its intent to acquire a leading Australian IT, business and management consulting group. This acquisition was expected to bring the best in class technology capabilities, global scale and a wide network of clients and partners across industries. (HCL Technologies, 2020)

GCI had been successful in competing by focusing on meeting clients' individual needs and providing excellent customer service. In 2019 and 2020, GCI was listed by the Channel Futures Managed Service Providers (MSP) 501 rankings, which recognizes the most elite and innovative IT services providers.

\section{Current Organizational Challenges}

GCI was involved in several company impactful environments with niche solutions to keep them stable. The narrow approach to gluing the different business units and business ventures together did not account for long term strategic objectives of global cohesiveness.

With multiple entities across different geographical areas, GCI was facing a multitude of challenges. The business had become much more diverse with the addition of international operations. Inconsistent processes, different systems, foreign currency, and poor reporting capabilities across the entire organization made it very difficult to scale the business and meet the demands of customers. GCI had to find a better technology solution that would allow them to expand and operate efficiently.

\section{OneGCI Global Support}

After receiving demand from large companies to provide services outside of the US, in 2015, GCI decided to expand their presence outside of the US and acquire FCS Global (FCS), a telecommunications company based in Cluj, Romania. FCS had a network operations center in Romania and was already supporting global clients throughout Europe, Middle East, and Africa.

In 2017, Global Convergence, Inc. won its first global contract outside of Romania to provide managed services and project services to a multi-billion-dollar global company. This contract allowed GCI to expand its global presence by providing services to the company's subsidiaries throughout Asia and Latin America. This expansion sparked a new marketing campaign, the OneGCI Collaboration Model, which focused on selling clients a single point of accountability for IT services across all global regions. For the 
campaign to be successful, GCI had to ensure the entire company was operating under a unified set of processes and procedures.

\section{Network Operations Center}

GCI operated its core services from two network operations centers located in Cluj, Romania and Tampa, FL. A network operations center (NOC) is a central location from which IT technicians manage, control, and monitor client networks. The overall function maintained optimal network operations by managing incidents and providing help desk support with the primary goal being to restore normal service operation to clients as quickly as possible while minimizing any adverse impacts on normal business operations. Incident management was a continuous process whereby incidents were logged, tracked, expedited, and resolved whereas the help desk function was responsible for logging client calls and tickets, dispatching the tickets to the appropriate teams (remote or on-site) for resolution, updating and closing the tickets in the ticketing system. The two NOCs utilized different ticketing systems and procedures to support each regions' operations making it difficult to support a global client efficiently. Multi-national companies were looking for a partner that could provide a "follow-the-sun" support model in which issues could be handled between offices in different time zones to increase responsiveness and reduce delays. GCI had an opportunity to gain a competitive advantage if the US and Romania NOCs were able to work seamlessly together; however, they would need to operate from a common system.

\section{Client Billing and Partner Payment Structures}

Clients required a combination of corporate location-specific, region-specific, and operational-specific billing, which vendors had to be able to provide an invoice structure that supported this hierarchy. GCI was able to accommodate most invoice requests from clients since they were setup to invoice locally from 18 countries (Exhibit 3). The current ticketing system used for US operations did not have the capability to recognize exchange rates outside of the billing entity's local currency; therefore, users had to manually convert data using the correct exchange rate prior to entering in the system. For example, the US company contracted to pay a partner $\$ 90$ Australian dollars for work performed for the US entity. A $\$ 90$ payment was submitted in the system; however, the partner was paid $\$ 90$ US dollars instead of Australian dollars. If using an exchange rate of .70, the payment should have been entered into the system as $\$ 63$ US dollars. This process was very time-consuming and confusing for the users and was not a scalable solution.

The Romanian ticketing system was able to transact in multiple currencies but did not have the features required to accommodate the specific billing requirements for the US clients and had not been customized for automation. GCI needed a billing system that worked for all their clients in every country. The system needed to enable billing in multiple currencies across different business units under a single contract and billing solution.

\section{Project Management}

Project services were led by project managers all over the world, regardless of the physical location of the sites. There was a central project management department that oversaw the assignment and setup of projects in the system. GCI utilized the US ticketing system to track project data; however, this system was just a transactional system used to bill the client and pay the partner. To manage a project efficiently, GCI needed a system that provided project estimation, status tracking, budgeting, collaboration, financial data, and portal access for clients. The current process required a combination of tools to track performance and manage efficiently. 


\section{Global Consolidated Reporting}

Most client contracts contained service level agreements (SLAs) that required GCI to provide clients a set of reports accurately showing their performance and compliance with the performance specifications outlined in the agreement. This proved to be difficult with the NOC in Romania using a completely different system to track incidents and provide help desk support for global clients. It was also a manual effort for the Finance team to provide consolidated financial data from both systems. Having a single system could provide a centralized view into the company's global operation with up-to-date revenue and cost information.

\section{The Technology}

If there's a problem, there's a technology GCI was willing to implement to resolve it. This process follows GCI's culture of short term tactile resolution rather than long term strategic implementation. They encountered some big decisions to consider which weighed:

- Change the technology or change the business process

- Enhance the existing technology or replace it

- Conform to the customer or let the customer conform

\section{What is a Ticketing System?}

Any company providing IT services needed to have a systematic process for handling client issues. GCI was no exception.

For GCI, a robust, efficient, user-friendly ticketing system was central to providing GCI's clients with high quality service. Globally they had multiple types and needed to consider the best route going forward.

Regardless of company, the goal of any ticketing system was to trace the life of a use case or business process which identified key stakeholders, attributes that described what was affected, what actions had been or will be taken upon it, and finally the status of that use case or business process. Ticketing systems came in many forms including: Incident handling, problem management, request fulfillment, change request process, configuration item management, and project management.

Differences in the types of ticketing systems:

- A Request was an ask for something new or enhancement that did not impact an in-use service. - Example: A user wanted an additional computer monitor in order to be more productive

- An Incident was typically a loss of use or efficiency in an existing service for a single user. - Example: A user was suddenly and unexpectedly unable to send email from Outlook

- A Problem was a loss or diminished use of a Service for a broader population. Problems were typically generated when multiple incidents reported similar symptoms. Those incidents were attached to the Problem ticket in a parent/child fashion.

- Example: Multiple users were suddenly and unexpectedly unable to send email 
- A Change Request was a modification to one or more existing Services/Solutions/Applications and were subject to approval and coordination. It may have required the Service to incur an outage.

- Example: A software vendor released a security patch, and the IT administrator had scheduled its installation during the application's normal maintenance window

- Configuration Item (CI) was an individual attribute of a Service/Solution/Application

- Example: The front doors of a business were set to automatically unlock at 8am and automatically lock at $6 \mathrm{pm}$. The 'front doors' are a CI \& their locking times are a CI. They may have been tied together in a parent/child relationship.

- Project Management was the lifecycle of development which may have included labor tracking, scheduling, and cost deduction.

It was important to understand how different but intermingling these systems would be. The same CI was 'tagged' or attached to an incident, problem, request, or change request as a way of tracking the impact of the CI over the course of its life. This was important as it helps to ensure information was not lost \& added transparency and accountability to the work performed in a company.

For example, if a User unexpectedly found the Front Doors were unlocking at 9am instead of 8am, they would have filed an Incident ticket. During the investigation, the Technician looked up the CI 'Front Doors'. They saw a child CI 'Locking Times' linked to the 'Front Doors' CI. A recent 'Change Request' ticket was attached to the 'Locking Times' CI that indicated an approval to update the lock timings. The Technician then reported back to the User that their issue was by design. The Technician would also use the Incident as a feedback datapoint for the original Change Request requestor as an indicator of the change being poorly communicated to the wider audience.

To the untrained eye they would have seen the different types of tickets to be a thing of madness, but their carefully coordinated use brings a healthy amount of precision and quantifiable data. (Exhibit 4)

\section{Alert FieldPoint}

GCI's United States business utilized a soon to be no-longer-supported on-premises edition Alert FieldPoint 6.5.7.6 for tracking work orders, technician scheduling, contract administration, and project management (Exhibit 5). It also integrated with Microsoft Dynamics Great Plains for fulfilling financial obligations with accounts receivable and accounts payable.

GCI's client maintenance contracts were entered into Alert which stipulated the price sheet for various offered services. Subcontractors, their serviceable geographical area, and their negotiated rate were entered into Alert for fulfilling GCI client contract needs.

When a client reported an incident, a work order was generated, which started the following process: (Exhibit 4)

1. Configuration Item with reported issue was noted.

2. A Contractor that worked in the geographical area of the Configuration Item's location was dispatched. 
3. Contractor closed the work order, indicating labor time (travel + onsite) and replacement parts installed. (Exhibit 6).

4. The work order was submitted into Great Plains for issuing (1) payment to Contractor at their negotiated rates (2) bill was submitted to client for payment or deducted from their pre-paid monetary commitment

Project billing and partner payments were tracked in Alert, but that was the extent of its utilization. Alert would not recognize currency - only values and was therefore unable to account for exchange rates outside the respective billing entity's local currency (Exhibit 3).

Since Alert FieldPoint was not capable of supporting multicurrency, there was no incentive to continue upgrading to a vendor supported version. Not being on a supported version added additional risks, which if realized, would have great business operational impact.

\section{ServiceNow}

ServiceNow was an option that GCI had been considering. It was commonly seen as the 'Cadillac' of ticketing systems for not only being capable, extensible with customization, but also one of the most expensive competitive options. ServiceNow had add-on modules for ticketing such as Change Requests, Problems, and Project Management. It would be installed as an on-premises solution or purchased as a Software as a Service (SaaS) cloud solution. Collectively it would provide most of the needs of GCI, but its price included a large collection of features that GCI would not immediately need.

Given ServiceNow's global adoption by the world, it would be extrapolated that it would be easily adopted by stakeholders such as their customers with minimized operational risk.

\section{CTS}

GCI's Romanian division used a custom-built ticketing solution called CTS. The transaction volume in Romania was small compared to US operations, but its implementation was utilized by over $50 \%$ of GCI's international offices. It was initially developed by a sole external programmer and could handle multi-currency needs and work order operations. GCI was typically a WinTel (Windows on Intel) IT shop, but CTS ran on a Linux operating system and was programmed in Ruby. CTS was not built for project management, had no native integration with Microsoft Dynamics Great Plains, and could not easily scale for accommodating the immediate needs of US operations.

\section{Mavenlink}

If GCI used CTS as its ticketing system internationally, the company would need a separate project management solution such as Mavenlink. This was a cloud software as a service (SaaS) project management solution that provided common PMO (project management office)

capabilities including: task schedule, task tracking, timers, budget \& forecasting, performance reporting, Gantt charts, and API integrations.

\section{GCl's Options}

Wilson and GCI leaders had known that their client management software would eventually need to be replaced as their company grew. But the issue was now becoming much more urgent with the upcoming loss of support for their main US ticketing system and the growing needs of their top client and its subsidiaries internationally. 
The current ticking system used by the US offices, Alert FieldPoint, would no longer be supported by the end of 2020. It would be possible to use without support, but it would still soon be unable to meet their needs. FieldPoint worked well as a ticketing system but did not work as well with project management and could not handle multi-currency. With new clients and the expected future business, handling multicurrency interactions would soon become critical. In addition, with multiple international offices, GCI needed a single client management software solution. Currently half the company used FieldPoint and half used the internally developed Romanian CTS software. Company executives wanted a single solution that would be able to grow with the company's enlarging networks connected to their largest client. They were already seeing the strain from having inadequate systems, and pressured Wilson to get this solved quickly. He had a few options (Exhibit 7).

\section{Expand the Romanian CTS software}

The CTS system was custom-made for the Romanian office. It handled ticketing and help desk functionality and was already processing multi-currency transactions. When the Romanian office was acquired five years ago, the division continued to use CTS, which meant that half of GCI was comfortable with CTS. The software worked very well for the Romanian division, which would likely fight hard to keep their current system. They had no urgent reason to change software.

Unfortunately, it was not clear that the CTS software would be able to scale for use throughout GCI internationally. The software was owned by an outside consultant, who would need to be hired to expand it to the other divisions. And while it worked well in one division, it had never had to handle the number of transactions that GCI would expect from it. CTS was not primarily a project management platform, so its developers would either need to expand its capabilities or the company would have to also purchase Mavenlink for project management. CTS was not cloud-based, which could limit the scalability and accessibility of the software. Finally, U.S. employees were not as familiar with it, and would need extensive training to switch to this software. Even so, expanding CTS would likely be the fastest way to get the entire company on one system.

\section{Purchase ServiceNow for entire company}

As a well-known global leader in cloud-based IT Service Management, ServiceNow was certainly capable of handling all aspects of ticketing, help desk, and client management that GCI would need. ServiceNow was already used by many of the current clients and was therefore familiar to many GCI employees. Some GCI employees had already been lobbying in favor of it.

The main drawback to ServiceNow was the cost. It would likely cost over $\$ 750,000$ to implement the software throughout the company which was significantly more expensive compared to alternative solutions with prices ranging between $\$ 30 \mathrm{~K}$ and $\$ 50 \mathrm{~K}$. ServiceNow also had a lot of functionality and features that GCI did not currently require. These features made the platform more expensive and possibly more cumbersome, but GCI may need these features soon if the company continued to expand. While it would be able to handle GCI's growth for many years, GCI may not yet need such a powerful and expensive solution.

\section{Purchase ServiceNow to replace FieldPoint, leave CTS in place in Romania}

Since CTS was working well for the Romanian teams, it might make sense to leave it alone for the time being. The most urgent issue was finding a replacement for FieldPoint. ServiceNow would be capable of replacing FieldPoint while also providing multi-currency and project management solutions. When the company grew, ServiceNow could eventually replace CTS. 
This would not satisfy one of the goals that GCI executives had, which was to integrate all the company under one client management software. But it might be a temporary solution that provided more time to integrate everyone.

\section{Delay the decision until a full gap analysis could be completed}

The urgency of the decision was perhaps causing GCI to lose sight of the best long-term solutions. As GCI was poised for further international growth, it might be a good time to step back and review their software goals. It was clear that FieldPoint could not handle what GCI needed, but Wilson had not had a chance to catalogue what the current software was lacking and what features were most important for company growth. While CTS was working in Romania, he had not had the opportunity to fully evaluate its benefits and costs for the rest of the company if it were to be used by everyone. Also, he had not been able to do a full cost-benefit analysis for ServiceNow. While it seemed expensive, it might be worth it if it could help GCI attain and keep valuable clients.

Delaying the decision would mean convincing the executives at GCI that the decision was important enough that it was worth the extra time. It could take months for a full gap analysis, and it was not clear that the current systems would be able to satisfy GCI's clients for that long.

\section{The Decision}

Wilson faced the following options:

1. Expand CTS for use throughout the entire company

2. Purchase ServiceNow, to replace FieldPoint and CTS, to provide a single fully integrated software platform for the entire company

3. Purchase ServiceNow to replace FieldPoint, but allow the Romanian division to continue to use CTS, which is still working well

4. Delay the decision to complete an in-depth gap analysis of the company needs (comparison of actual performance with potential or desired performance)

\section{References}

First Research. (2020). Industry Profile: Information Technology Services. Retrieved from http://www.firstresearch.com/Industry-Research/Information-Technology-Services.html.

GCI press release (2020). Global Convergence, Inc. (GCI) Ranked Among World's Most Elite 501 Managed Service Providers. Retrieved from https://www.globalconvergence.com/global-convergenceinc-gci-ranked-among-worlds-most-elite-501-managed-service-providers/

Grand View Research. (2019). IT Professional Services Market Size, Share, \& Trends Analysis Report By Type, By Deployment (On-premise, Cloud), By End Use, By Region, And Segment Forecasts, 2019 2025. Retrieved from https://www.grandviewresearch.com/industry-analysis/it-professional-servicesmarket. 
HCL Technologies.(2020, September 21). HCL Technologies Announces Intent to Acquire Leading Australian IT Solutions Company, DWS Limited. Retrieved from https://www.hcltech.com/pressreleases/press-releases-business/hcl-technologies-announces-intent-acquire-leading-australian

Incident management (ITSM). (2020, June 20). In Wikipedia. Retrieved 05:02, September 27, 2020, from https://en.wikipedia.org/w/index.php?title=Incident management $($ ITSM)\&oldid=963520802

NTT. (2019, October 1). Dimension Data Americas, NTT America, and NTT Security become NTT. Retrieved from https://hello.global.ntt/en-us/newsroom/dimension-dataamericas-ntt-america-and-nttsecurity-become-ntt

\section{Biographies}

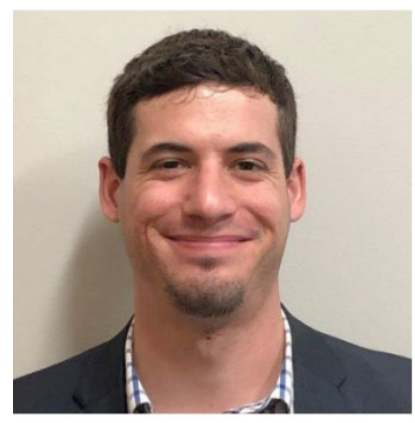

Jeremy Bess is a Director with Revenue Management Solutions who works with global restaurant chains to optimize profitability. He leads a department of analysts and consultants who examine pricing strategies and implementation to provide quicker and more accurate pricing guidance for thousands of restaurants. He is responsible for all contact and pricing strategies for thousands of eateries. He has worked for Revenue Management Solutions since 2014. Prior to that, he worked as an investment adviser representative with Jaffe Tilchin Wealth Management in Tampa. He also has published articles about restaurant operations and was a speaker at the 2017 World Tea Expo. Bess received a bachelor's degree in economics from the University of Tampa (2013).

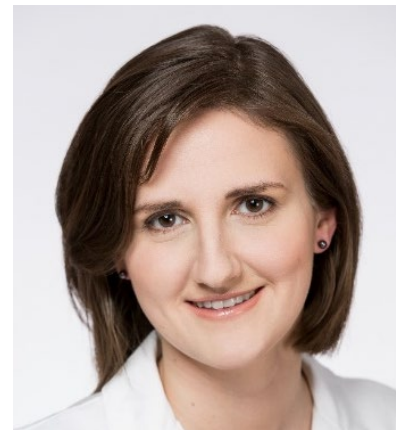

Deva Boone, MD founded the Southwest Parathyroid Center in Phoenix, AZ, the only center in the western U.S. dedicated solely to the treatment of parathyroid disease. Prior to this, she was the Medical Director and Senior Surgeon of the Norman Parathyroid Center in Tampa, FL. A board-certified physician, Dr. Boone is also a Fellow of the American College of Surgery and the American College of Endocrinology. She earned a Doctor of Medicine with honors in service in 2006 from Cornell University Medical College and a bachelor's degree from Cornell University in 2002. Dr. Boone completed both general surgery residency and endocrine surgery fellowship.

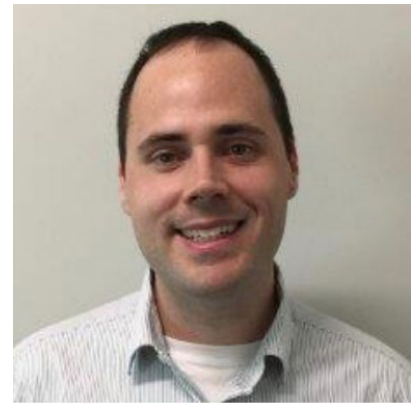

Chase Dafnis is a versatile cloud engineer at Microsoft who frequently dives into diverse environments. Since 2015, he has worked as a public sector Senior Premier Field Engineer. In this role, Dafnis leads, inspires and manages an inclusive customer base including military, state and local government, and educational institutions. As a "road warrior," he facilitates technical readiness trainings, architecting long-term cloud strategies and modernizing customer data centers and operations to reduce overhead. His leadership qualities include stimulating customer C-level executives into adapting their businesses' systems to cloud technologies, developing new 
marketable offerings and adapting internal operations to a consumption model. He is a mentor to technical and management staff while fostering a growth mindset. Dafnis received a bachelor's degree in Management of Information Systems from the University of South Florida (2008).

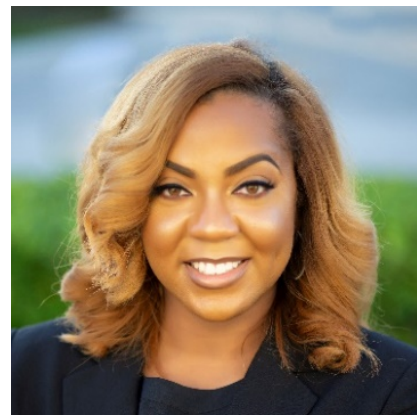

As global controller at New Era Technologies, Kristiaan is responsible for corporate accounting, financial reporting, audit, treasury, and tax strategy. She is a resourceful and dynamic professional who has exceptional strengths in management, financial analysis, and accounting. She has honed the ability to identify alternative solutions and processes and is highly organized in the way she executes corporate strategies. Her career spans more than 15 years of varied experience in financial management and business leadership. Previously, she served as vice-president of finance for Global Convergence and accounting manager for Quality Distribution. Gaines holds a master's degree in accounting from the University of Alabama at Birmingham (2009) and a bachelor's degree in accounting from the University of Alabama at Tuscaloosa (2006). She was designated a Certified Public Accountant in Alabama in 2011.

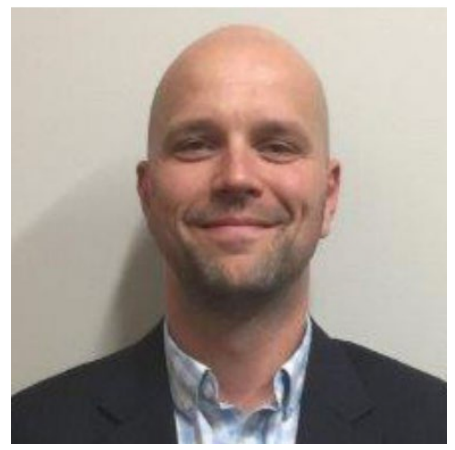

Dan Kiger has served in various security/manager roles supporting government contracts. He currently is a project officer with Arma Global in Tampa. He has been in that position since 2016. He has served as a team leader for multiple world-wide projects to answer customer requirements and has volunteered for and was selected to manage and support highly visible projects. Kiger received a bachelor's degree in communication from Saint Vincent College in Pennsylvania (2003) and attended the John Cabot University in Italy, Fu Jen Catholic University in Taiwan, and the Defense Language Institute in California. 


\section{Exhibit 1: GCINet Options and Outcomes}

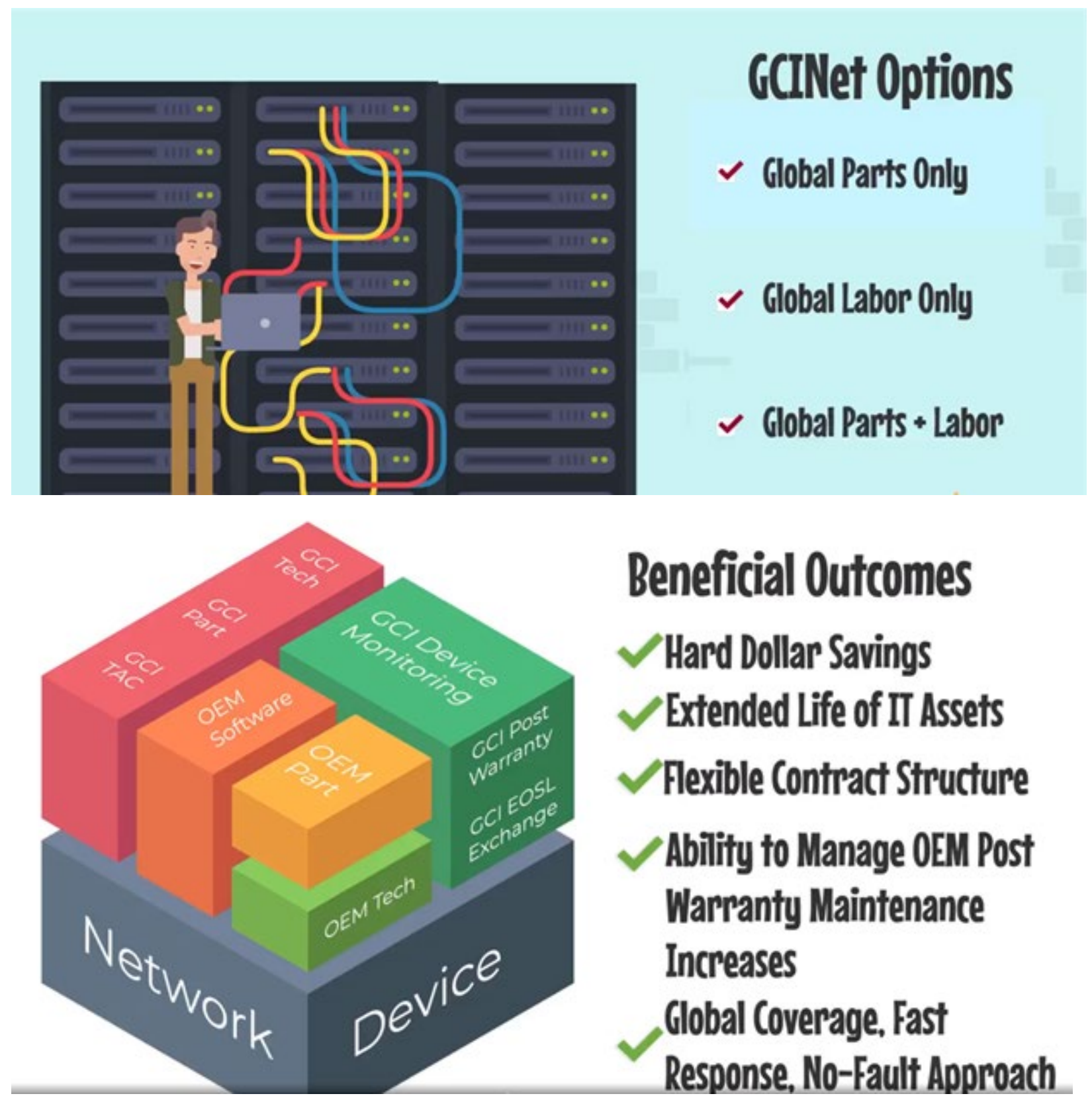

Source: Global Convergence. (2020, September 27). GCI Entities [pdf]. Retrieved from internal files of Global Convergence (not publicly available). 


\section{Exhibit 2: GCl's Global Competitors}

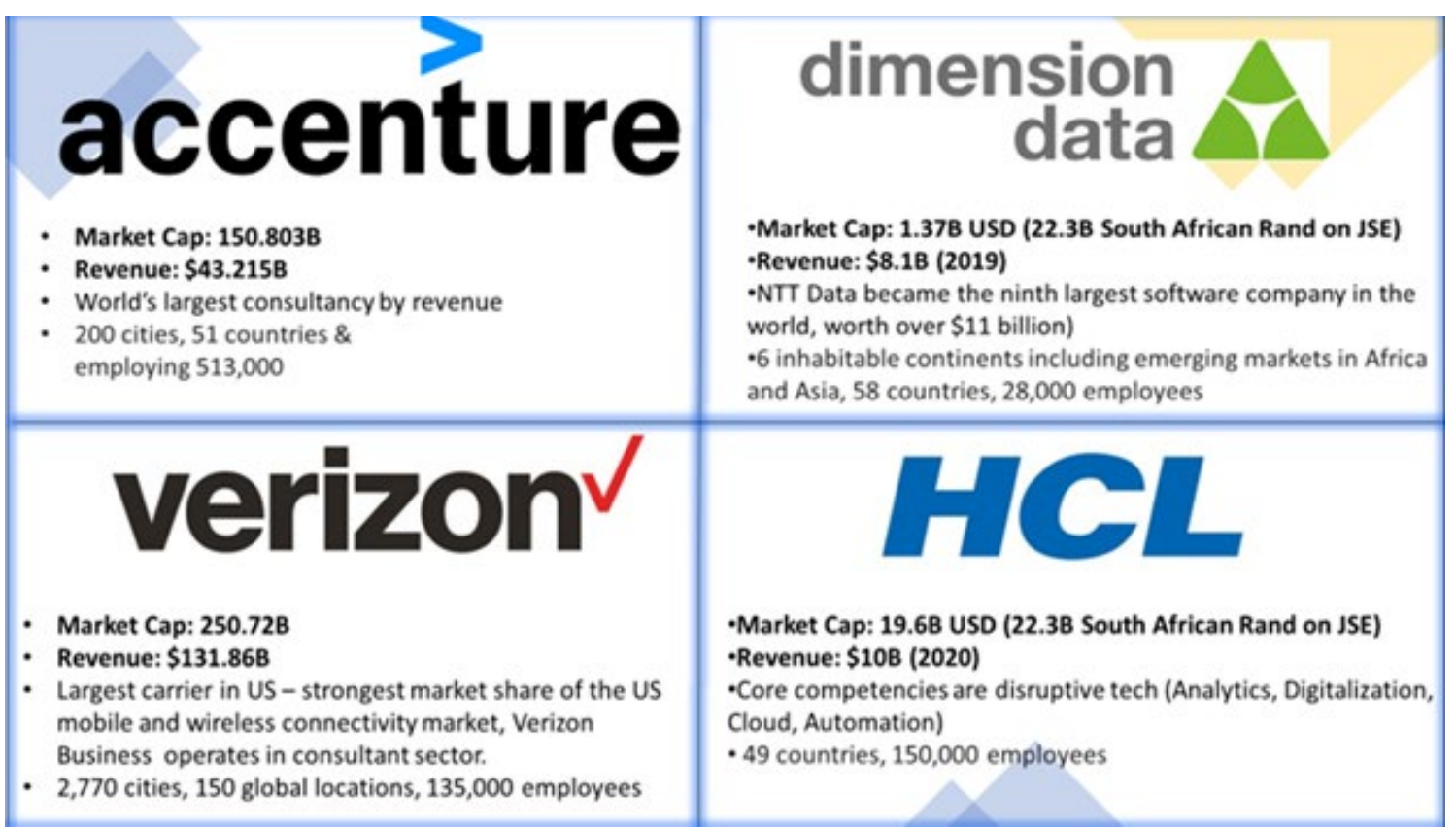

Source:

Accenture Revenue 2006-2020 (2020). Macrotrends.net. Retrieved September 26, 2020 from https://www.macrotrends.net/stocks/charts/ACN/accenture/revenue.

Bhasin, H. (2019, January 21). SWOT analysis of Verizon. Marketing91. Retrieved September 26, 2020 at https://www.marketing91.com/swot-analysis-verizon/.

Dimension Data Financials (n.d.). Craft.co. Retrieved September 26, 2020 from https://craft.co/dimension-data/metrics.

Fast Facts. (n.d) HCL Technologies. Retrieved September 26, 2020 from https://w ww.hcltech.com/investors/fastfacts.

HCL Technologies (n.d.). Forbes.com. Retrieved September 26, 2020 from https://www.forbes.com/companies/hcltechnologies/\#c7a06573e93f.

Verizon Communications Inc. Form 10-K . (2019). United States Securities and Exchange Commission. Retrieved September 26, 2020 from https://www.sec.gov/Archives/edgar/data/732712/000073271219000012/a2018q410-k.htm.

Verizon Market Cap 2006-2020 (2020). Macrotrends.net. Retrieved September 26, 2020 from https://www.macrotrends.net/stocks/charts/VZ/verizon/market-cap. 


\section{Exhibit 3: GCI Billing Entities}

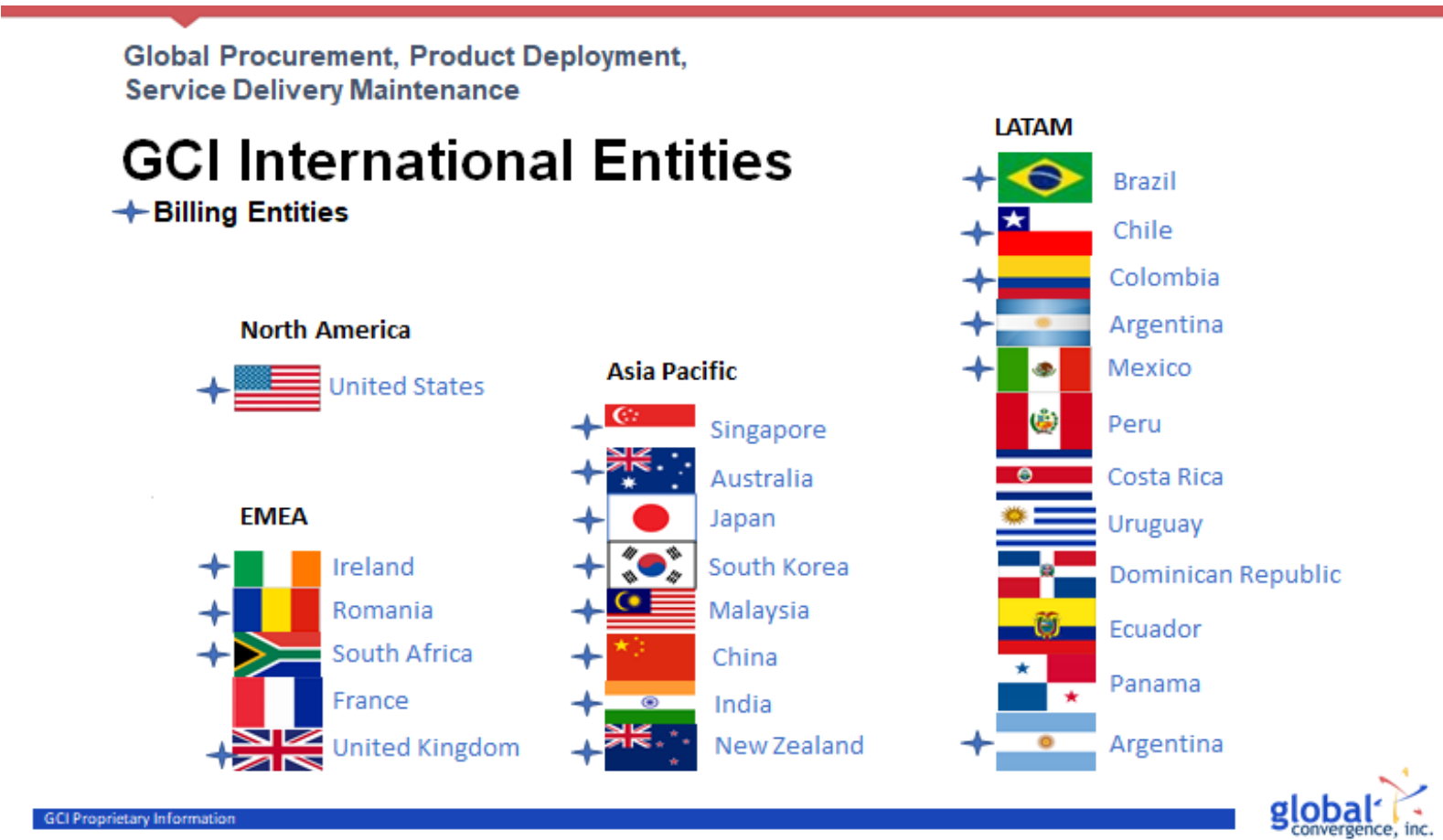

Source: Global Convergence. (2020, September 27). GCI Entities [pdf]. Retrieved from internal files of Global Convergence (not publicly available). 
Exhibit 4: Customer Problem Fulfillment - Process Chart

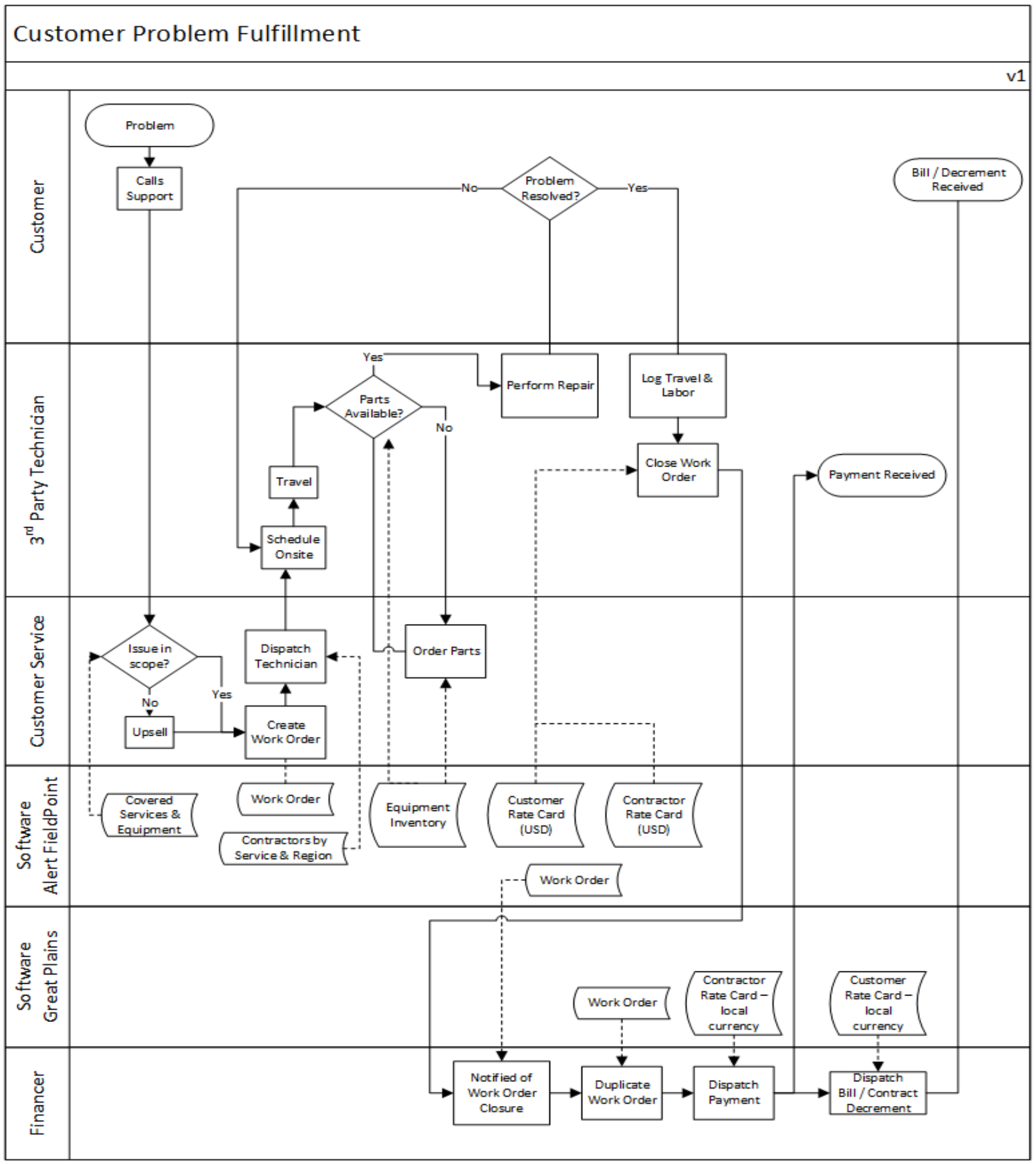

Source: "Dafnis, Chase T" (2020, September) Business Process Flow for Customer Problem Fulfillment. Interview between Cary Wilson \& Kristiaan Gaines on GCI processes 


\section{Exhibit 5: Alert FieldPoint - Brochure}
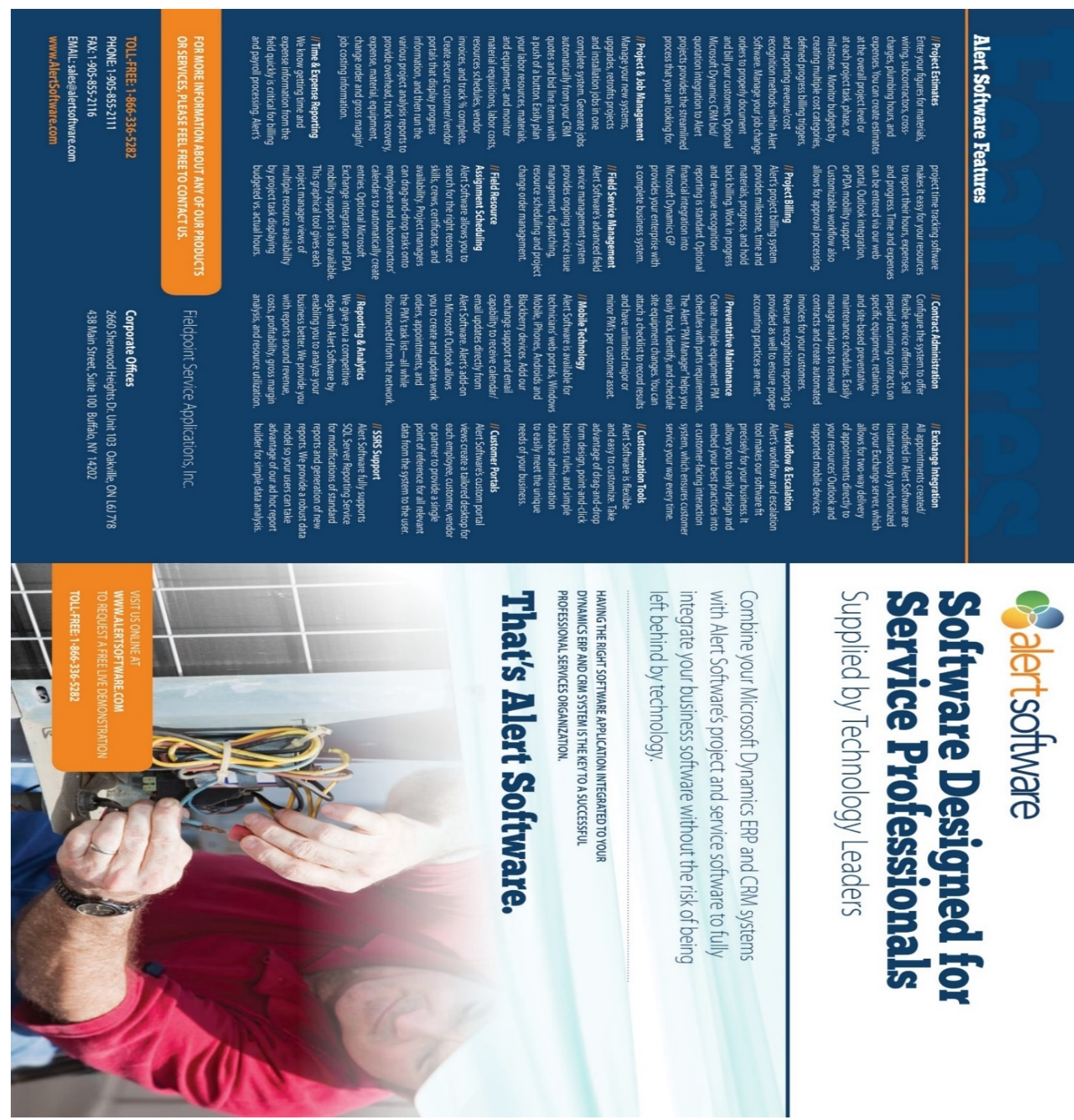


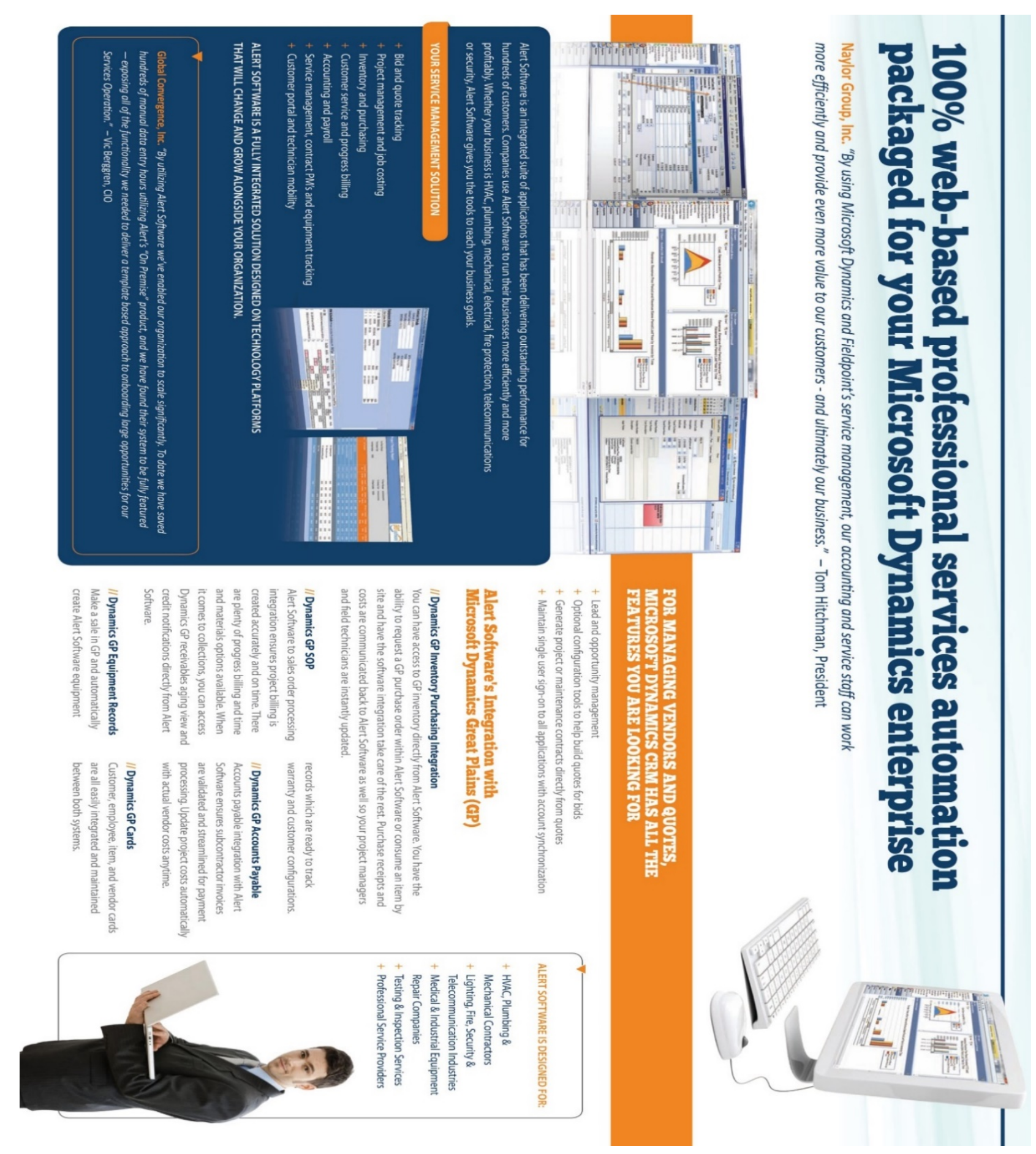

Source: CAL Business Solutions (2020, September). Alert Software [pdf] https:/www.calszone.com/marketplace/wp-content/uploads/AlertSoftware-Brochure.pdf 


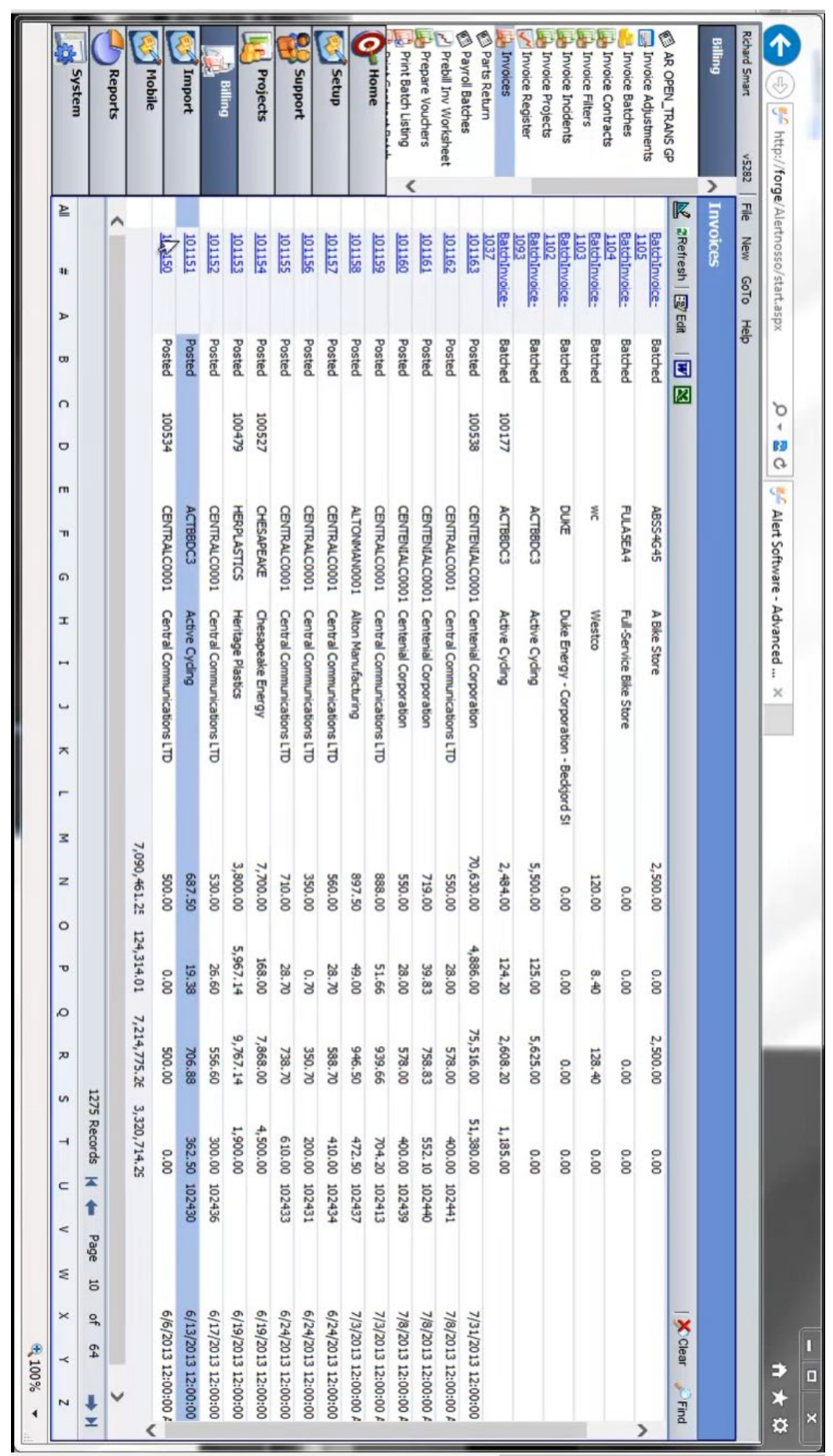

Source: [Fieldpoint]. (2013, July 12). Alert Software - Field Service and Contract Management. [Video file]. https://www.youtube.com/watch? $\mathrm{v}=\mathrm{drD} 06 \mathrm{zS} 5 \mathrm{Ni} 8$ 
Exhibit 7: Comparison of Software Options

\begin{tabular}{|l|l|l|l|l|}
\hline \multicolumn{1}{|c|}{ Product Name } & \multicolumn{1}{c|}{ CTS } & \multicolumn{1}{c|}{ ServiceNow } & \multicolumn{1}{c|}{ Alert } & \multicolumn{1}{|c|}{ Mavenlink } \\
\hline Price Range & $\$ 30,000$ & $\$ 750,000$ & N/A & $\begin{array}{l}\$ 50,000+\text { annual } \\
\text { maintenance }\end{array}$ \\
\hline $\begin{array}{l}\text { Annual Maintenance } \\
\text { Cost* }\end{array}$ & $\begin{array}{l}\text { \$90K internal } \\
\text { labor cost }\end{array}$ & $\begin{array}{l}\text { Est } \$ 150 \mathrm{~K} \\
\text { annual license } \\
\text { fees }\end{array}$ & None* & $\begin{array}{l}\text { \$45K annual } \\
\text { license fees }\end{array}$ \\
\hline Service Support^ & $\begin{array}{l}\text { Help Desk; } \\
\text { Project Mgt^^}\end{array}$ & $\begin{array}{l}\text { Help Desk; } \\
\text { Project Mgt }\end{array}$ & Help Desk & Project Mgt \\
\hline Business Size & SMB & Enterprise & SMB & SMB/Enterprise \\
\hline User Range & Unlimited & Fee per user & Unlimited & Fee per user \\
\hline Multi-Site & Yes & Yes & Yes & Yes \\
\hline Multi-Currency & Yes & Yes & No & Yes \\
\hline Deployment & On-Premise & Cloud & On-Premise & Cloud \\
\hline $\begin{array}{l}\text { Dynamics GP } \\
\text { Integration* }\end{array}$ & $\begin{array}{l}\text { Development } \\
\text { required* }\end{array}$ & Yes & Yes & $\begin{array}{l}\text { Development } \\
\text { required* }\end{array}$ \\
\hline Industry Recognized & No & Yes & No & Yes \\
\hline
\end{tabular}

Source: “Gaines, Kristiaan” (2020, September) Comparison of Software Options.

*Alert will no longer provide annual maintenance support once the product is deprecated.

$\wedge$ Further development required for CTS to support project management. 